\title{
Nutraceutical and Cosmeceutical Potential of Seaweed Derived Fucoxanthin
}

\author{
A. SIL*AND U. DASGUPTA ${ }^{1}$ \\ Division of Agricultural Chemicals, ${ }^{1}$ Division of Genetics, Indian Agricultural Research Institute, Delhi 110012, India
}

\section{Sil et al.: Nutraceutical and Cosmeceutical Potential of Fucoxanthin}

\begin{abstract}
The marine ecosystem is considered a potentially mysterious reservoir of biodiversity consisting of a broad spectrum of bioactive constituents, whose potential is still under research for pharmaceuticals, nutraceuticals and cosmeceuticals. Fucoxanthin, a carotenoid, can be found in the brown seaweeds and is recognized to show promising and exclusive biological activities. Subsequent consumption and absorption of fucoxanthin leads to its accumulation in the white adipose tissue and helps to depict anti-obesity effects via upregulation of thermogenesis through uncoupling protein 1 expression and mitochondrial activation. Linking with anti-obesity, fucoxanthin shows antidiabetic potential by insulin resistance signalling pathways. Fucoxanthin is also reported to control carcinogenesis via regulating several biomolecules and signalling pathways which are intermittently linked with either apoptosis or cell cycle arrest or suppression of metastasis. In addition, it can act as a potential antioxidant by scavenging toxic free radicals and also aid in the treatment of neurodegenerative, hepatic and cardiovascular dysfunctions. Fucoxanthin has a profound role in the cosmetic industry for its mosquito repellent activity and protective effects on the blood vessels, skin and bones. Therefore, the current review provides the recent available scientific literature on Fucoxanthin regarding its health-promoting effects, modulating mechanism and future potential to use it as a commercially viable drug in nutraceutical and cosmeceutical applications.
\end{abstract}

Key words: Nutraceutical, anti-obesity, anti-cancer, antioxidant, cosmeceutical, anti-diabetic

Seaweeds, being the photosynthesizing biomass, residing in the intertidal zone, are classified into the red (rhodophytes), green (chlorophytes) and brown (phaeophytes) algae. Amidst them, most consumed are the brown seaweeds, in both fried, dried or salad forms and due to high nutritional values, whole parts of the algae can be utilized as a foundation of various functional foods, cosmetics, other dietary and medicinal supplements ${ }^{[1]}$. Further, these seaweeds are the source of potentially bioactive components which helps in the promotion of human and animal health ${ }^{[2]}$. Seaweeds are considered to be a rich source of nonstarch polysaccharides, principally essential minerals and dietary fibers, primary and secondary metabolites and consequently, they are currently marketed as "superfood", a term defining health benefits with prolific nourishing profile and enriched in bioactive phytochemicals ${ }^{[3]}$. While the primary metabolites are involved directly in managing physiological benefits, under normal conditions, the secondary metabolites are recently paid huge attention because of its antioxidant

*Address for correspondence E-mail: sil.anirban2014@gmail.com and other admirable properties ${ }^{[4]}$. Carotenoids are one of such potential antioxidants, located in photosynthesizing organisms and play a significant role in photochemical events. $\alpha$-Carotene, $\beta$-carotene, violaxanthin, lutein, zeaxanthin, fucoxanthin (Fx) and neoxanthin has been testified and found in numerous categories of seaweeds ${ }^{[5]}$. Amongst these, Fx, a photosynthetic pigment, only occurred in algae and diatoms (Bacillariophyta) especially in the cold and temperate environments, not in telluric plants. Besides having photosynthesis and photoprotection nature, Fx also has health assistances (fig. 1). This review focusses on the up-to-date scientific works concerning the bioactive implication of Fx, including its nutraceutical and cosmeceutical benefits.

This is an open access article distributed under the terms of the Creative Commons Attribution-NonCommercial-ShareAlike 3.0 License, which allows others to remix, tweak, and build upon the work non-commercially, as long as the author is credited and the new creations are licensed under the identical terms

Accepted 01 July 2021

Revised 23 March 2021

Received 29 October 2020

Indian J Pharm Sci 2021;83(4):618-633 


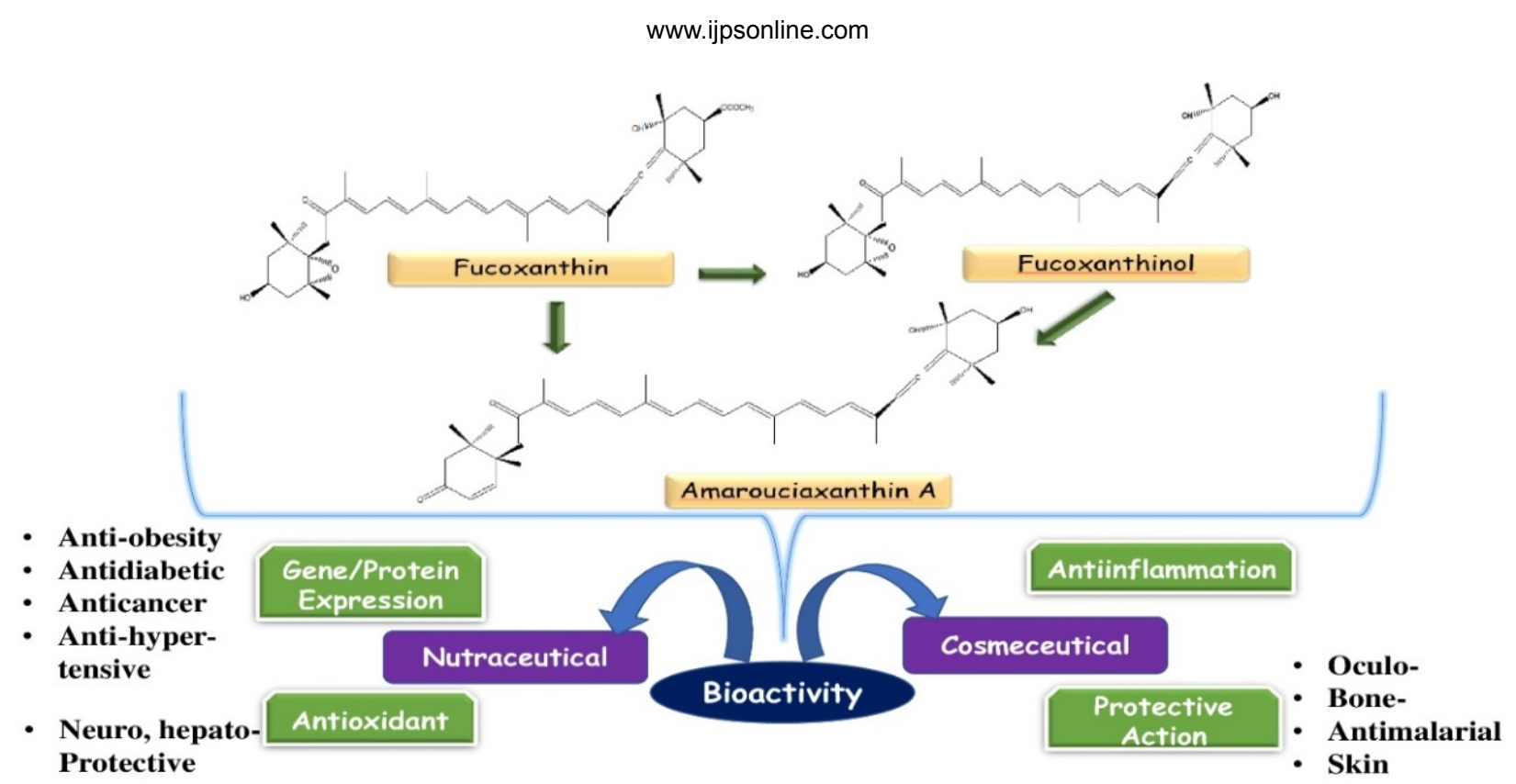

Fig. 1: Bioactivity of Fx

\section{MAJOR SOURCES OF FUCOXANTHIN AND ITS EXTRACTION}

Fx is a xanthophyll with an inimitable chemical framework. It has an uncommon allenic bond with a 5,6-monoepoxide configuration in its complex ${ }^{[6]}$ which enhances its superiority over other carotenoid molecules. Various studies have reported the extraction and further screening of bioactivity of Fx from the nautical Phaeophyta involving Cystoseira hakodatensis, Alaria crassifolia, Padina tetrastromatica, Fucus serratus, Ishige okamurae, Fucus vesiculosus, Hijikia fusiformis, Cladosiphon okamuranus, Saccharina japonica, Myagropsis myagroides, Eisenia bicyclis, Petalonia binghamiae, Laminaria ochotensis, Sargassum heterophyllum, Sargassum fulvellum, Sargassum horneri (S. horneri), Sargassum siliquastrum, Kjellmaniella crassifolia, Undaria pinnatifida (U. pinnatifida) and the diatoms including Cylindrotheca closterium, Chaetoseros species, Phaeodactylum tricornutum and Odontella aurita ${ }^{[]]}$. Wastes generated from the cultivated parts of Saccharina japonica (Kombu) have proved to be a promising biogenic source for extraction of Fx and approximately 10 times (fresh weight) of Kombu waste provides a total of $1490 \mathrm{~g}$ of Fx with recovery ratio reaching about $82 \%{ }^{[8]}$. Moreover, isolation of Fx from fresh Undaria species showed the dominance of alltrans $\left(\sim 88 \%\right.$ ) geometrical isomeric forms ${ }^{[9]}$. The major sources of Fx were found in Cystoseira hakodatensis (Yendo) and $S$. horneri when a comparative study on 15 brown algal samples near the northern coast of Japan, revealed the presence of Fx in higher quantities in both the species with 240 and $370 \mathrm{mg} / 100 \mathrm{~g}$ dry weight (d.w. $)^{[10]}$. Moreover, periodic variations in the lipid constituents in these 2 species depicted the trend of Fx content starting with exponential growth from October/November, reaching a maximum plateau in December at Matsushima and February at Usujiri and a sudden decline thereafter. The most probable reason for this could be the strong correlation between the photosynthetic activity coupled with Fx and light and temperature where low light during winter encourages production of Fx via xanthophyll-cycle pathway that involves Fx formation from zeaxanthin via antheraxanthin, violaxanthin. Moreover, maturation period, nutritional profile of water and depth along with major factors are responsible for differential accumulation of functional lipids in these two areas. Furthermore, through stimulating the optimal growing environments, like light, temperature and depth, a loft in the amount of Fx (193 mg/g d.w.) was reported in S. horneri cultured in cold water region of Usujiri ${ }^{[11]}$. Due to the complex structure of substrates, it is pretty difficult to extract the bioactive molecules from them ${ }^{[12]}$. Moreover, the requirement of a large quantity of toxic organic solvents, presence of impurities, high capital costs and time-consuming nature, the conventional extraction has been exchanged now with cutting-edge methods, like enzyme-assisted extraction, pressurized liquid extraction and supercritical fluid extraction ${ }^{[13]}$. Further, when the extraction is continued with edible oils, it protects the bioactive carotenoids from degradation and therefore, can be used as raw food materials without any decontamination ${ }^{[14]}$. Recently, effective extraction of Fx was reported from S. horneri and rate 
of extraction of Fx was more efficient and satisfactory with short-chain (tributylin, C4 and tricapronin, C6) TAG (triacylglycerol), medium-chain (tricaprylin, C8) TAG (MCT) oils and fish oil as compared to other 12 types of edible oils including rice germ and bran, rapeseed, corn, sesame, linseed and soybean ${ }^{[15]}$.

\section{NUTRACEUTICAL POTENTIAL OF FX}

\section{Anti-obese potential:}

Consumption of imbalanced diet for a long period of time amend lipid digestion and results in an accretion of intra-abdominal fat, therefore leads to various obesity and overweight associated metabolic ailments, like dyslipidemia, hypertension, diabetes mellitus and cardiovascular disorders ${ }^{[16]}$. Subsequently, the discovery of effectual stratagems is the need of the hour to avert overweightness. A bunch of molecular mechanisms can modulate obesity with diet comprise of plummeting food ingestion via controlling gut and adipose signals; hindering excess nutrient accumulation; enhancing thermogenesis to disintegrate energy from foods as heat and tempering lipid synthesis/lipolysis or adipose tissue differentiation/apoptosis ${ }^{[17]}$. Fx can lessen the concentrations of hepatic and plasmatic triglycerides and also influence cholesterol-regulating enzymes like acyl-coenzyme A and 3-hydroxy-3-methyl glutaryl coenzyme A reductase ${ }^{[18]}$. Further, it can positively alter the expression of genes allied with lipid digestion such as when rats are supplemented with Fx, the messenger ribonucleic acid (mRNA) expression of hepatic acetyl coenzyme A (acetyl-CoA) carboxylase (ACC) decreases. When the enzyme is active, malonyl$\mathrm{CoA}$ is produced from acetyl CoA via irreversible carboxylation. Malonyl-CoA can impede an important step in $\beta$-oxidation of fatty acids via inhibiting a mitochondrial enzyme carnitine palmitoyltransferase 1 (CPT1), which can catalyse the transfer of acyl group of long-chain fatty acyl-CoA to 1-carnitine, thereby forming acylcarnitines and transferring long-chain fatty acids (LCFA) to mitochondria for oxidation. This leads to a subsequent decrement in the transport of LCFA to muscle and heart mitochondria, thereby resulting in increasing levels of free fatty acid, accumulation of fats in white adipose tissue (WAT) and decreasing heart and muscle's oxidizing capability. Fx can take a major role in this regard as it upregulates CPT1 and thereby preventing and restraining these symptoms ${ }^{[19]}$. Furthermore, supplementing Fx diet can also help in decreasing expression of mRNA of fatty acid synthase (FAS), a multi-enzymatic protein promoting the synthesis of fatty acids. Recent investigations suggested that FAS, though a possible oncogene and poor chemotherapeutic agent, may have some involvement in endogenous ligand production specific to the nuclear receptor, peroxisome proliferator-activated receptoralpha (PPAR- $\alpha$ ), which is the bull's eye of the fibric acid derivatized drugs provided against hyperlipidemia, so it is presently being utilized as a conceivable drug target for the ailment of different metabolic dysfunctions ${ }^{[20]}$. Fx also mediates regulatory control over cholesterol uptake by the liver via inducing expression of sterol regulatory element-binding protein (SREBP) and downregulating of scavenger receptor class $\mathrm{B}$ member 1 (SR-B1) and low-density lipoprotein (LDL) receptor as reported by Beppu et al..$^{[21]}$ as when they fed Fx to a type 2 diabetic mouse model, diabetic KK and lethal yellow $\left(\mathrm{A}^{\mathrm{y}}\right) \mathrm{KK}-\mathrm{A}^{\mathrm{y}}$ mouse; it showed a decline of $60 \%$ and $80 \%$ of LDL and high-density lipoprotein (HDL) cholesterol uptake. Moreover, digestible Fx markedly enhanced mRNA expression of protein convertase subtilisin/kexin type 9 (PCSK9). It further augments intracellular perversion of LDL receptor (LDL-R) in lysosomes.

At the time of development of functional foods for the treatment of obesity, sympathetically modulated thermogenesis upregulation is the most targeted counterpart. And one major factor in the thermogenesis is the expression of uncoupling protein 1 (UCP1). Beige adipocytes of WAT and brown adipose tissue are the site of induction of UCP1 expression. Despite a bunch of mechanisms have been proposed for the potential of Fx as an anti-obese drug, adaptive thermogenesis through induction of UCP1 in adipose tissues is the most commonly reported target site of $\mathrm{Fx}^{[13]}$. The major role of thermogenesis via UCP1 is to increase body metabolism to produce heat and therefore UCP1 dissipate the $\mathrm{pH}$ gradient as generated due to oxidative phosphorylation and release excess heat in terms of chemical energy. The expression of UCP1 is further influenced by numerous factors, like adrenergic stimulation, beta-3 $\left(\beta_{3}\right)$ agonists, cold and thyroid hormones. Dysfunctioning of any single factor may result in weight gain that is directly associated with obesity development ${ }^{[22]}$. Fx augments thermogenesis by increasing the amount of heat energy, released in fat tissue. In an experimental feeding of $0.2 \%$ Fx containing Undaria lipids to mice model, not only the expression of UCP-1 mRNA has been detected in their WAT, but also thermogenesis and lipolysis inducing $\beta_{3}$-adrenergic receptor $\left(\beta_{3} \mathrm{Ad}\right)$ were found to be promoted ${ }^{[23]}$. In some systems supplementing with Fx saw an increase in the expression of peroxisome 
proliferator-activated receptor gamma co-activator 1 (PGC-1), which along with $\beta_{3}$ Ad positively regulates UCP1 and also causes mitochondrial biogenesis leading to increased metabolic rate ${ }^{[24]}$ (fig. 2). So, this adrenergic stimulation amplified sensitivity towards stimulation of sympathetic nerve response which further leads to upregulation of oxidation of fats in adipose tissue.

Supplementation of Fx in human also reported positive results in terms of weight loss as a significant increase in the resting energy expenditure (REE) had been observed in human when fed with $4.0 \mathrm{mg} / \mathrm{d}$ Fx consistently for $16 \mathrm{w}$. Further, the significant decrement in body weight in obese human leads to prevention of metabolic diseases via down-regulation of hepatic and inflammatory response markers like glutamic pyruvic transaminase (GPT), C-reactive protein (CRP), Gamma-Glutamyl Transpeptidase $(\gamma \mathrm{GT})$, glutamic oxaloacetic transaminase (GOT) ${ }^{[25]}$. A human clinical trial was conducted on obese individuals having average weight of $100 \mathrm{~kg}$, in which daily supplementation of $2.4 \mathrm{mg}$ Fx was provided and after a few weeks, the REE increased, thereafter a noteworthy decrement in body fat and weight, serum lipid levels and liver fat contents were observed ${ }^{[26]}$. A group of moderately obese individuals were supplemented with Fx for $4 \mathrm{w}$ with a daily dose of $3 \mathrm{mg}$ and the visceral fat area as well as body mass index showed drastic reduction after $4 \mathrm{w}^{[27]}$. Comparative standards of entire fat mass, hypodermal fat zone, abdominal perimeter and right thigh perimeter also became expressively subordinate after ingestion of $1 \mathrm{mg}$ Fx compared to placebo cluster. A group of scientists investigated that mRNA expression of monocyte chemoattractant protein-1 (MCP-1) was enriched in high obese mice but was controlled below threshold in Fx rich lipid fed groups ${ }^{[28]}$. Woo et al. ${ }^{[29]}$ also revealed that gene expression of palmitoyl CoA (Peroxisomal acyl-coenzyme A oxidase 1 (ACOX1)), acyl-CoA oxidase 1 and PPAR- $\alpha$ and $\gamma$ were apparently revised by Fx. Moreover, during the comparison of oppressive effects of Fx and its metabolites on 3T3L1 adipose tissue differentiation, amarouciaxanthin A depicted the sturdiest outcome, tailed by fucoxanthinol and $\mathrm{FX}^{[30]}$. On another side, a report by Kang et al. ${ }^{[31]}$ confirmed the effect of $\mathrm{Fx}$ on adipocytes differentiation subject to different stages like early (0-2 d), intermediate $(2-4 \mathrm{~d})$ and late stage (4-7 d). Fx inconsistently encouraged adipocyte separation during the first $2 \mathrm{~d}$ through enhancing PPAR- $\gamma$, sterol regulatory element binding protein-1c (SREBP-1c), CCAAT/enhancerbinding protein $\alpha(\mathrm{C} / \mathrm{EBPR} \alpha)$ and adipocyte fatty acid-binding protein expression, but it reduced its level in the later stages. Additionally, fucoxanthinol $(\mathrm{FxOH})$ was stated to exhibit greater suppression of adipocyte differentiation via down-regulating PPAR $\gamma$. Recently, downregulation of stearoyl-coenzyme A desaturase-1 (SCD1) has been implemented in inhibition of overweightness and in the augmentation of leptin and insulin sensitivity. Moreover, after $2 \mathrm{w}$ of Fx feeding to KK-A $\mathrm{A}^{\mathrm{y}}$ mice, significantly decreased levels of serum leptin and therefore potentially prevent hyperleptinemia, though oppressive effects of Fx on hepatic SCD1 and body weight gain have not been detected in obese/obese mice ${ }^{[32]}$.

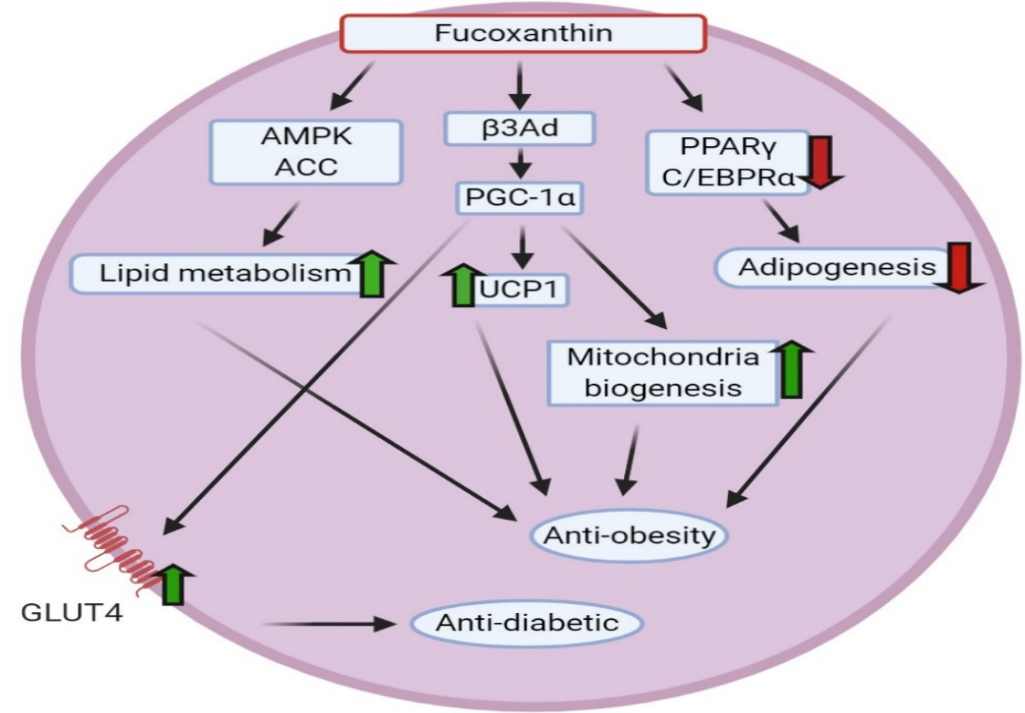

Fig. 2: Molecular mechanism of antidiabetic and anti-obesity activities of $\mathbf{F x}$

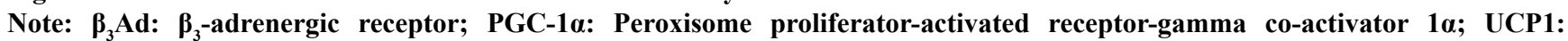
Uncoupling protein 1; AMPK: AMP-activated protein kinase; ACC: Acetyl CoA carboxylase; PPAR $\gamma$ : Peroxisome proliferatoractivated receptor $\gamma$; C/EBPR $\alpha$ : CCAAT/enhancer-binding protein $\alpha$; GLUT4: Glucose transporter type 4 
Recently Koo et $a l .{ }^{[33]}$ documented the anti-obese potential of characterized Fx powder, obtained from seaweed Phaeodactylum tricornutum. The dosedependent decrement of body weight, organ weight, fat mass, adipose weight, intracellular lipid contents and adipocyte size was observed in high fat diet (HFD) fed C57 black 6 (C57BL/6J) mice along with UCP1 upregulation and PPAR $\gamma$ downregulation were perceived in treated clusters. Besides, in the same mouse model, feeding with Fx containing HFD alleviated dysbiosis of gut microbiota significantly via constraining the development of obesity-/inflammation inducing microbes like Erysipelotrichaceae and Lachnospiraceae while endorsing the growth of Bifidobacterium, Lactobacillus, Lactococcus and some butyrate-generating microbes ${ }^{[34]}$. Supplementation of a lipophilic ethanolic Phaeodactylum tricornutum extract in mice showed Fx accumulation in adipose tissues, thereby resulting in lowering of obesity and the mechanism is directly linked to lowering of expression of genes related to lipid uptake, fat tissue expandability (mesoderm specific transcript (Mest)) in WAT depots, enhancing expression of genes connected to oxidation of free fatty acids and thermogenesis (UCP1 and CPT1) in subcutaneous/interscapular adipose tissue ${ }^{[35]}$. Further supplementation of 4 Fx control treatments, normal chow diet (NCD), HFD, NCD 11+Fx (NCDF) and HFD+Fx (HFDF) in Bagg Albino (BALB)/c mice pointedly altered the faecal and cecal microbiota composition. Moreover, lowering in Firmicutes/ Bacteroidetes ratio and the abundance of S24-7 and Akkermansia were identified to be among the major gut microbiota modulating events associated with the anti-obesity potential ${ }^{[36]}$. Chang et al. ${ }^{[37]}$ investigated that $\mathrm{Fx}$ is capable of inhibiting lipids accumulation in FL83B hepatocytes via significantly suppressing lipid accumulation and decreasing lipid peroxidation in hepatocytes. Furthermore, Fx significantly increased phosphorylation of adenosine monophosphate activated protein kinase (AMPK) and decreased activity of acetylCoA carboxylase for regulating fatty acid synthesis. A lipid drug delivery scheme was proposed in which suggestions were provided to incorporate lipids from $U$. pinnatifida onto phospholipid via encapsulation and this might result in an additional enhancement in the anti-obesity potential of Fx on KK-A $\mathrm{A}^{\mathrm{y}}$ mouse model. Therefore, these results demonstrated that Fx employs different responses during various stages of differentiation and prevents glucose assimilation in fully grown adipocytes.

\section{Anti-diabetic potential:}

Dietary incorporation of HFD induces levels of blood sugar and insulin as fats get accumulated in the abdominal region. This over-aggregation in abdominal adipose tissue in overweight persons upsurges the exudation of bioactive mediators from the tissues, known as chemokines/adipokines. Further, development of obesity results in enrichment in proinflammatory chemokines like MCP-1, interleukin-6 (IL-6), tumour necrosis factor-alpha (TNF- $\alpha$ ) etc. As the reports suggested that these pro-inflammatory adipokines are directly involved in persuading insulin sensitivity via inducing infiltration of macrophage into the gut adipose tissue, causing chronic low-grade inflammation and moreover TNF- $\alpha$ and saturated fatty acids initiate a paracrine loop to upregulate these chemokines secretion and inflammation in adipose tissue ${ }^{[38]}$. In this respect, Maeda et al. ${ }^{[28]}$ discovered that stimulated ingestion of Fx in over-weighted/diabetic KK-A $\mathrm{A}^{\mathrm{y}}$ mice significantly inhibited macrophage infiltration, enhanced insulin confrontation and reduced levels of post-prandial blood glucose, partially at least, via downregulation of mRNA expression of abdominal adipokines and plasminogen activator inhibitor-1 (PAI-1) ${ }^{[13]}$. Additionally, the other proposed mechanism for modulating the diabetic signalling of Fx is the glucose transporter type 4 (GLUT4) regulation (fig. 2). Expression of GLUT4 gets upregulated in the presence of insulin and different other stimuli, therefore, rapidly migrates to the plasma membrane from the intracellular site and endorses glucose uptake ${ }^{[39]}$. Fx added to a HFD can completely normalize levels of GLUT4 mRNA expression in the skeletal muscle of KK-A mice. Moreover, a noteworthy enrichment of GLUT4 levels was reported in the extensor digitorum longus muscle of the diabetic mouse model along with upregulation of PGC- $1 \alpha$ (co-activator in mitochondrial biogenesis) expression ${ }^{[40]}$. Specificity on diabetes has been demonstrated by feeding a Fx added high-fat diet and normal diet to $\mathrm{C} 57 \mathrm{BL} / 6 \mathrm{~J}$ mice. Blood glucose level normalization has been observed with high-fat diet in conjugation with $\mathrm{Fx}^{[28]}$, but it didn't go for glucose level reduction in C57BL/6J mice served with normal $\operatorname{diet}^{[41]}$. Moreover, Woo et $a l .{ }^{[42]}$ demonstrated that lessening of insulin: glucagon may be partially accountable to the sinking of blood glucose levels by Fx. Fx might also upgrade alterations in lipid absorption and insulin confrontation brought by a HFD, partly at least, by plummeting mass of visceral fats, hepatic glucose production and lipogenesis, hyperinsulinemia, along with controlling activities of hepatocellular glucose-regulating enzymes ${ }^{[43]}$. 
Furthermore, FxOH, being a major metabolite of $\mathrm{Fx}$, decreased expression of cyclooxygenase-2 (COX-2) mRNA and TNF- $\alpha$ inducible nitric oxide synthase (iNOS) along with the production of protein by palmitic acid-treated Ralph and William's cell line 264.7 (RAW 264.7) macrophage-like cells ${ }^{[44]}$. When a diabetic $\mathrm{db} / \mathrm{db}$ mice are treated with iNOS inhibitor, it stimulates reversion of hyperglycaemia and increased insulin sensitivity, depicting that down-regulating expression of iNOS mRNA in the raw macrophages can not only target inflammation prevention but is also responsible for treating type-2 diabetes. Pharmacological inhibition of COX-2 decreases IL-6 in adipose tissue that further promotes insulin resistance. Fx induced robust deterrent actions towards pancreatic $\alpha$-amylase in a dose-dependent manner which induces 3T3-L1 pre-adipocytes differentiation ${ }^{[45]}$.

Among the insulin signalling pathways for modulating glucose metabolism and diabetes control, insulin receptor substrate 1 (IRS-1)/phosphatidylinositol 3-kinase (PI3K)/protein kinase B (AKT) (IRS-1/PI3K/ AKT) pathway leads from the front and its initiation is indispensable for the upregulation of IRS (insulin receptor signalling) transduction ${ }^{[46]}$. In a study, Fx supplementation can purposefully alleviate the PI3K, IRS-1, p-Akt and AMPK protein levels in the liver and the skinny muscles without upsetting the overall Akt levels, therefore complementing with its action on insulin confrontation. In addition, activation of glycogen synthase kinase 3 beta (GSK3 $\beta$ ) can encourage the glycogen synthase (GYS) phosphorylation that further results in the decrement of the activity of GYS and synthesis of glycogen ${ }^{[47]}$. Along with AMPK activation, Fx diet can significantly enhance the glucokinase (GK) mRNA levels and correspondingly decrease mRNA expression of phosphoenolpyruvate carboxykinase (PEPCK), that are further key enzymes in hepatic gluconeogenesis and glycolysis, respectively. Changes in GK and PEPCK levels in the liver may also be directly associated with the hypoglycaemic action of $\mathrm{Fx}$ in obese/diabetic mouse model ${ }^{[48]}$. Besides, Jung et al. ${ }^{[49]}$ demonstrated that Fx could preliminarily upsurge insulin signalling by increasing levels of the insulin-stimulated receptor activation, most probably owing to its protein tyrosine phosphatase 1B (PTP1B) inhibitory potential. Further, it strongly inhibited advanced glycation end-product (AGE) formation and moderately subdued human recombinant aldose reductase (HRAR) and rat lens aldose reductase (RLAR), signifying that it has an auspicious potential to completely eliminate hyperglycaemia-associated diabetic complications.

\section{Anti-oxidant potential:}

Similar to other carotenoids, Fx is also able to quench singlet $\mathrm{O}_{2}$ species particularly involving physical interactivity, in which the conjugated polyene structure of Fx absorbs the surplus energy migrated from the singlet oxygen species. The number of conjugated double bonds generally determines the radical scavenging activity of the carotenoids and in this regard, the presence of allenic bond is solely responsible for antioxidant potential of Fx. A controversy happened between two groups of scientists, in which, Sachindra et al. ${ }^{[50]}$ concluded that $\mathrm{Fx}$ and its major metabolites, halocynthiaxanthin and fucoxanthinol has 9 conjugated double bonds and still has pretty lower oxygen radical thrust as compared to $\beta$-carotene (11 conjugated double bonds), whereas, a scientific investigation by Hirayama et al. ${ }^{[51]}$ showed no or little variation in scavenging ability amidst $\mathrm{Fx}$ and $\beta$-carotene. Moreover, lipid hydroperoxide formation is prevented more efficiently by $\mathrm{Fx}$ in a single $\mathrm{O}_{2}$ - mediated plasma lipid oxidation than $\alpha$-tocopherol and $\beta$-carotene. Amongst the other chemical and structurally suitable features that are attributed towards radical scavenging activity of Fx are the presence of hydroxyl group, epoxide group etc. ${ }^{[52]}$. The synergy of polyphenols and Fx showed anti-oxidant potential in systems having no cells $\left(\mathrm{O}_{2}{ }^{-}, 2,2^{\prime}\right.$-azino-bis(3-ethylbenzothiazoline-6sulfonic acid (ABTS), 2,2-diphenyl-1-picrylhydrazyl (DPPH) and oxygen radical absorbance capacity (ORAC)) and in triggered macrophages (RAW 264.7), along with in ex vivo analyses in erythrocytes and plasma of rats. Fx has the potential to scavenge free organic radicals in the electronic resonance spin signalling intensities like DPPH, 12-doxyl-steric acid (12-DS), nitrobenzene with linoleic acids radical adduct (NB-L) with $28 \%, 66 \%$ and $57 \%$ inhibition capacity, respectively ${ }^{[33]}$. Effective inhibition of reactive oxygen species (ROS) generation, oxidative deoxyribonucleic acid (DNA) damage, peroxide-induced apoptosis etc. are influenced, especially due to the presence of Fxinduced catalase. Under anaerobic conditions, Fx can react with DPPH equimolarly while $\beta$-cryptoxanthin, lycopene, zeaxanthin, lutein and $\beta$-carotene rarely react with DPPH and therefore had no practical quenching ability but when the environment shifts to oxic one, then only a part of Fx quench and most importantly sensitivity also decreases as compared to $\beta$-carotene ${ }^{[54]}$. Sangeetha et al. ${ }^{[55]}$ started a comparative 
study on the effects of $\beta$-carotene and Fx on different indicators which generally induce oxidative stress (glutathione transferase, sodium-potassium adenosine triphosphatase $\left(\mathrm{Na}^{+}-\mathrm{K}^{+}\right.$-ATPase) and catalase etc., $)$and their probable role in conquering lipid peroxidation subsequently due to retinol deficit in rats. Experimental results evidenced that both Fx and $\beta$-carotene safeguard damage of cell membrane due to lipid peroxidation by lessening the activity of $\mathrm{Na}^{+}-\mathrm{K}^{+}$-ATPase and enhancing the Glutathione-S-transferase (GST) and catalase activities at the microsomal level and tissue levels, thereby protecting from retinol deficiency. Further inspection that both $\beta$-carotene and Fx possibly can curtail the vitamin $\mathrm{D} 2$ oxidation by singlet $\mathrm{O}_{2}$ species quenching. Fx was also able to prevent the oxidative rupture in humanoid polymorphonuclear leukocytes (PMLs), thrust radicals and improve glutathione (GSH) to glutathione disulphide (GSSG) ratio $^{[56]}$. Further, Foo et al. ${ }^{[57]}$ tried to conserve the anti-oxidant potential of Fx rich extract, obtained from Chaetoceros calcitrans, through microencapsulation. The obtained results indicated that amongst the microencapsulated formulations, 1:1 gum Arabic:maltodextrin with $40 \%$ carrier agent and $1 \% \mathrm{w} / \mathrm{w}$ Tween 20 as emulsifier can serve as the most successful encapsulating agent for preserving Fx, both in spray dried and freeze dried conditions. Further, Fx decreased the ROS formation in kidney fibroblasts ${ }^{[58]}$, human promyelocytic leukemia cell line (HL-60) cells and mouse macrophage RAW 264.7 cells, human hepatoma cell line (HepG2) cells $^{[59]}$, normal hepatic L02 cells, human keratinocyte cells (HaCat) etc. Fx can also amend inflammations and radical-induced oxidative stress in amyloid $\beta 42$ ((A $\beta 42)$-induced cellosaurus cell line (BV-2) microglia 168 cells $^{[60]}$. It is important to mention that Fx having $\alpha$, $\beta$-unsaturated carbonyl group, can function as Michael acceptor that may further react with Keap one proteins in nuclear factor erythroid 2-related factor $2(\mathrm{Nrf} 2)$ pathways. A recent investigation by Liu et al.${ }^{[61]}$ reported that $\mathrm{Fx}$ boosted expression of heme oxygenase-1 (HO-1) and $\mathrm{NAD}(\mathrm{P}) \mathrm{H}$ dehydrogenase quinone 1 (NQO1) in murine hepatic cellosaurus cell line (BNL CL.2) cells via activating the Nrf2/antioxidant response element (ARE) (Nrf2/ARE) system pathway and recommended that Fx might act as a potential prooxidant to be used in medicinal treatments. Besides all the above, Fx showed hepatic anti-oxidant potential via increasing expression of NQO1 and HO-1 via activating the Nrf related factor 2 response signalling pathway (fig. 3) $)^{[62]}$.

\section{Anti-tumor/cancer potential:}

Fx can persuade inhibitory potential on cancerous cells by means of apoptosis induction. The general

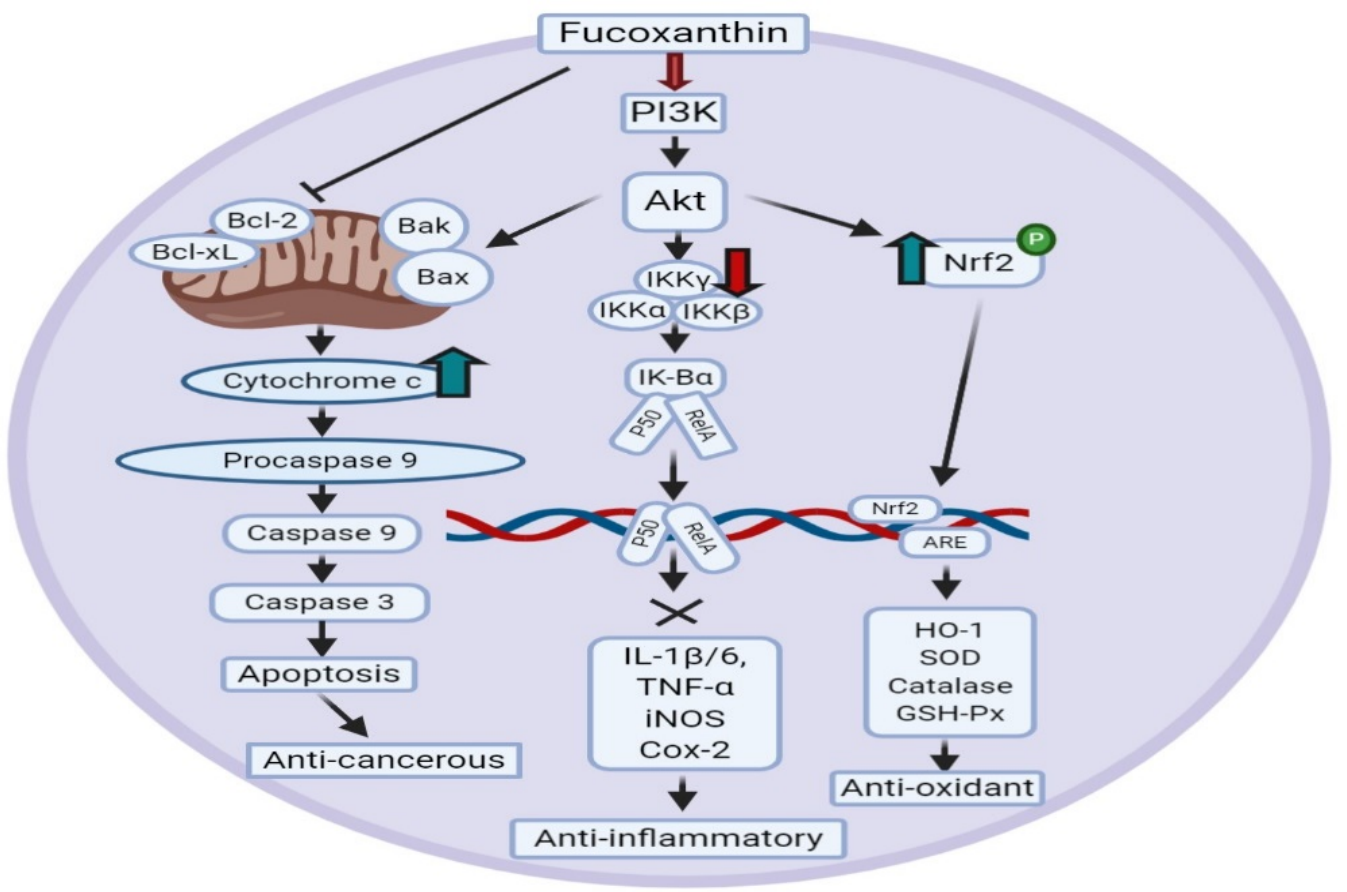

Fig. 3: Molecular mechanism of anti-cancerous, anti-inflammatory and anti-oxidant activities of $\mathbf{F x}$

Note: PI3K: Phosphatidyl inositol 3-kinase; Akt: Protein kinase B; Bcl-2: B-cell lymphoma 2; Bcl-xL: B-cell lymphoma-extra-large; Bak: Bcl-2 homologous antagonist/killer; Bax: Bcl-2 associated x protein; Nrf2: Nuclear factor erythroid 2-related factor 2; ARE: Antioxidant response elements; HO-1: Heme-oxygenase 1; SOD: Superoxide dismutase; GSH-Px- Glutathione peroxidase; IKK:

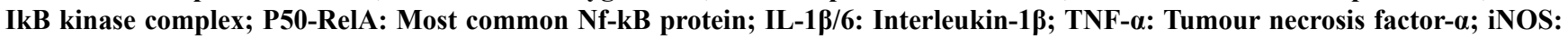
Inducible nitric oxide synthase; COX-2: Cyclooxygenase-2 
suggested mechanism is that higher dose of Fx results in the cleavage of Poly [adenosine di-phosphate (ADP)ribose] polymerase 1 (PARP-1) and caspase proteins (including 3,7,8 and 9), through PARP oxidase and ROS formation in cells thereby leading to apoptosis in human T-cell leukemia virus type 1 (HTLV-1), HL60 , leukaemia inducing T-cells and primary effusion lymphomas ${ }^{[3,64]}$ while at low doses, it was reported to upregulate cyclin-dependent kinase inhibitor $\mathrm{p} 21^{\text {(WAF1/ }}$ Cipl) and B-cell lymphoma extra-large (Bcl-xL) and hinder cyclin $\mathrm{D}$ and Janus kinase/signal transducers and activators of transcription (JAK/STAT), causing arrestation of multiple tumor cell lines growth ${ }^{[65]}$.A group of scientists observed the cytotoxicity of astaxanthin, neoxanthin, Fx, violaxanthin and siphonaxanthin against the cultured cells of HL-60 lines and a remarkable inhibitory effect was perceived in case of Fx in comparison to the lutein, zeaxanthin, astaxanthin and $\beta$-carotene ${ }^{[66]}$. Further, 15 different categories of carotenoids existing in foodstuffs $(\alpha$-carotene, phytoene, astaxanthin, $\xi$-carotene, phytofluene, capsanthin, $\beta$-carotene, $\beta$-cryptoxanthin, lycopene, canthaxanthin, lutein, violaxanthin, zeaxanthin, $\mathrm{Fx}$ and neoxanthin) were assessed against the growth of anthropic prostate cancer cell lines (lymph node carcinoma of the prostate (LNCap), human prostate cancer cell line (PC-3) and human prostate cancer cell line (DU 145)) and amidst them, carotenoids having allenic bonds in their molecules such as Fx and neoxanthin depicted greater reduction of growth of the cell lines ${ }^{[67]}$. Additionally, both fucoxanthinol and halocynthiaxanthin induced apoptosis of breast cancer cell line (MCF-7) cells, HL60 cells and human colon cancer cell line $(\mathrm{CaCo}-2)$ colon cancer cell lines eventually superior as compared to Fx. An assay was done by Ishikawa et al. ${ }^{[64]}$ on the better anti-proliferative properties of $\mathrm{Fx}$ and $\mathrm{FxOH}$ on leukaemia virus type 1-infected human T-cell lines and adult leukaemia T-cell in vitro. Fx could also terminate the in vitro differentiation of cancerous cells by bringing about morphogenic alterations like cell volume decrement, rounding up, nuclei fragmentation and chromatin condensation, apoptotic body formation whenever they are exposed to anthropic lung epithelial cell line (A549) and non-small cell bronchopulmonary carcinoma line (NSCLC-N6) ${ }^{[68]}$. Recent efforts have been directed towards the chemopreventive actions of Fx against colorectal cancer. A metabolite of Fx, fucoxanthinol, can show anti-proliferative actions against a bunch of colorectal tumour cell lines involving human colorectal carcinoma cell line (HCT116), Caco-2, colon adenocarcinoma cell lines
(Colo205), colon carcinoma cell lines (SW620), colorectal adenocarcinoma cell lines (DLD-1), colon adenocarcinoma cell line (WiDr) etc., ${ }^{[69]}$. The cancer stem cells, including epithelial cell adhesion molecule $\left(\mathrm{EpCAM}^{\mathrm{high}}\right)$ and a multifunctional cell surface adhesion receptor (CD44 high) cells, are also found to be completely diminished by the anti-proliferative action of $\mathrm{FxOH}^{[70]}$. Suppression of tumor sphere formation, transport and expansion of colorectal tumour lines, downregulation of metastasis, extracellular adhesion, arrestation of cell cycle and cell proliferation etc., are the major dose-dependent activity of $\mathrm{Fx}^{[71]}$. Additionally, inhibiting overexpression of integrin signalling by Fx can induce anchorage-dependent apoptosis in colorectal cancer (CRC) cells. Besides, Fx prohibited the growing of serum free cell culture of neuroblastoma cell line (GOTO) cells in human by arresting resting state $\left(\mathrm{G}_{0}\right)$-growth 1 phase $\left(\mathrm{G}_{1}\right)\left(\mathrm{G}_{0}-\mathrm{G}_{1}\right)$ phase and reducing expression of proto-oncogene protein ( $\mathrm{N}$-myc gene). $\mathrm{Fx}$ and fucoxanthinol also lessened viability of the primary effusion lymphoma cells including human monocytic cell line (TY-1) and body cavity based lymphoma cell line (BCBL-1) through stopping cell cycle and hindering nuclear factor kappa-light-chain-enhancer of activated $\mathrm{B}$ cells $(\mathrm{NF}-\mathrm{\kappa} \mathrm{B})$ activation, inhibiting Akt pathways, activator protein-1 and downregulating cell cycle mediators and anti-apoptotic proteins in the lymphoma cells. Zhang et al. ${ }^{[72]}$ provided that Fx diminished the vigour and viability of human urinary bladder cancer (EJ-1) cells by inducing apoptosis, DNA damage, activating caspase-3 activity. It also blocked the development of lamellipodia and inhibited the metastatic potential of the extremely protrusive murine melanoma cell line (B16-F10) by clamping down the expression of CD44/C-X-C chemokine receptor type 4 (CXCR-4) and matrix metallopeptidase 9 (MMP-9) at mRNA and protein levels, respectively. Again, Das et al. ${ }^{[73]}$ studied the mechanistic molecular model of Fx against the hepatocellular carcinoma utilizing HepG2 cell lines and they reported that here Fx inhibited only $\mathrm{G}_{0} / \mathrm{G}_{1}$ cell cycle, but no induction of apoptosis was observed. This further indicated that Fx has the cytostatic potential other than cytocidal in the human HepG2 cell lines. Further, a conclusion derived from this study recommended that suppression at both transcriptional level and proteolytic level would be the most probable reason behind reduction in levels of cyclin Ds and inhibition of the activity of cyclin D/cyclin-dependent protein kinase 4 (Cdk4) in HepG2 cells and therefore might lead directly to the cancer prevention activity. Fx also exhibited significant suppression of human 
ovarian carcinoma cell line (A2780) by stimulating apoptosis, reducing cell proliferation and transfer and mediating Akt/mammalian target of rapamycin (mTOR) suppression ${ }^{[74]}$. Recently, a study reported that lower and non-toxic concentrations of Fx could trigger C6 glioma cell differentiation, therefore, preventing human glioblastoma multiforme (GBM).

In an animal experiment, $\mathrm{Fx}$ induced by 1,2-dimethylhydrazine dihydrochloride and azoxymethane showed significant potential towards the inhibition of growth and expansion of anomalous crypt foci, which is a preneoplastic indicator for CRC cells ${ }^{[75]}$. Administration of Fx exclusively stifled carcinogenic growth in a xenograft model of CRC, deduced colonic lesions and reduced quantity of colorectal polyps than to the control mouse ${ }^{[76]}$. Various reports suggested that spontaneous liver carcinogenesis have been prevented by $\mathrm{Fx}$ administration in $\mathrm{C} 3 \mathrm{H}$ Heston $(\mathrm{C} 3 \mathrm{H} / \mathrm{He})$ male mice and also exhibited anticancer inducing actions in a two stage tumorigenesis experiment in the Institute of Cancer Research (ICR) mice's skin, initiated with 7,12-dimethylbenz[a]anthracene and promoted with mezerein and 12-O-tetradecanoylphorbol-13-acetate (TPA). Besides, Fx was testified to prevent duodenal cancer in mice implemented with N-ethyl-N'-nitro-Nnitrosoguanidine ${ }^{[77]}$.

Moreover, the conjunction of Fx with another spectrum of drugs can prevent cancer better, utilizing apoptosis induction, cell cycle arrestation, increased intercellular gap junction communication and autophagy induction. Fx inhibits the activity of anti-apoptotic proteins B-cell lymphoma 2 (Bcl-2) and B-cell lymphoma extra-large (Bcl-xL) and downregulates the Akt pathway leading to upregulation of pro-apoptotic proteins Bak, Bax. These pro-apoptotic proteins lead to the release of cytochrome c. This ultimately causes the formation of apoptosome complex leading to cleavage and activation of caspases, causing apoptosis in tumour cells (fig. 3). The autophagy of tumour cell lines can be further induced by Fx via various pathways, like reducing P-glycoprotein 1 (P-gp), cytochrome P450 3A4 (CYP3A4) promoter activation, ROS generation and cellular uptake along with PI3K/Akt/NF-אB pathway suppression ${ }^{[78]}$.

\section{Anti-inflammation potential:}

A response, which is usually generated as a selfdefensive mechanism against stimuli of any pathogen, is known as the inflammatory response ${ }^{[79]}$. When the body characterizes such pathogens, various bodily mechanism attracts a large number of leukocytes like monocytes, neutrophils, mast cells etc. in the inflamed area, triggering the generation of inflammatory cells via mediators and sometimes generates nitric oxide and superoxide anion radicals ${ }^{[80]}$. This complex radical generation process makes it a harmful one. The role of an anti-inflammatory agent in this regard is to decrease the inflammatory response via vanquishing inflammatory cytokines and other mediator's production. Scientists claimed that Fx could inhibit these mediators in RAW 264.7 macrophages via reducing levels of cytokines, nitric oxide, prostaglandin $\mathrm{E}_{2}$, phosphorylation of MAPK (mitogen-activated protein kinases) and inhibiting NF-kB. Fx played a significant role in preventing immediate-type allergens and rapid inflammatory responses as reported via inhibition of antigen-influenced accumulation of high-affinity immunoglobulin $\mathrm{E}(\mathrm{IgE})$ receptor and thereby activating degranulating signals of mast cells ${ }^{[81]}$. Su et al. ${ }^{[82]}$ depicted that Fx decreases the expression of inflammatory cytokines including interleukin-1 $\beta$ (IL-1 $\beta$ ), TNF- $\alpha$ and IL-6 by downregulating the Nf-kB pathway (fig. 3), in a preventative manner in the lipopolysaccharide-induced sepsis mice model. Further, the results revealed that Fx influenced anti-allergic potential is directly associated with the NF- $\mathrm{BB}$ signalling regulation in RAW 267.4 macrophage cells. However, recently, the effect of Fx on inflammation bowel disorder, ulcerative colitis was investigated. In vivo treatment of 50 and $100 \mathrm{mg} / \mathrm{kg} / \mathrm{d}$ Fx pointedly provides protection against dextran sulphate sodium (DSS)-induced slow bodyweight lessening, also exhibited preventive action on the DSS-induced increase of disease activity index (DAI) as well as shortening of the colon. Additionally, Fx treatment in mice also decreases the overexpression of the DSS-induced inflammatory molecules involving $\mathrm{NF}-\kappa \mathrm{B}$ and $\mathrm{COX}-2^{[83]}$. Hwang et al. ${ }^{[84]}$ investigated the potential of antiinflammation of fucoidan having a less molecular weight (LMF) and Fx having high stability (HS-Fx) in a lipopolysaccharide-induced Caco-2 inflammatory cell line co-cultured with Bifidobacterium lactis. They found that both the bioactive molecules initiated the probiotic growth and decreased gut epithelial inflammation to a great extent. Also, the amalgamation of HS-Fx and LMF intensely improved the colonic epithelial barricade along with immunogenic functions against the lipopolysaccharide induction through hindering TNF- $\alpha$ and IL-1 $\beta$ while upgrading interferon gamma (IFN- $\gamma$ ) and IL-10. Furthermore, a combination of $5 \mu \mathrm{M}$ rosmarinic acid (RA) and $5 \mu \mathrm{M}$ Fx controlled the 
alluring response in a ultraviolet B (UV-B) irradiated anthropic immortalized $\mathrm{HaCat}$ keratinocytes via downregulating inflammasome constituents like ASC, caspase- 1 and NLR family pyrin domain containing 3 (NLRP3) and producing IL-1 $\beta^{[85]}$. Fx from U. pinnatifida was used against mouse ear oedema and erythema by Khan et al. ${ }^{[86]}$ and induction using phorbol myristate acetate showed an exclusive inhibition of both inflammatory oedema and erythema around $85 \%$ and $78 \%$ respectively ${ }^{[86]}$. Besides, the methanol extract of the $U$. pinnatifida reduced the acetic acid-influenced writhing response in the analgesic test, along with it confirmed antipyretic action in yeast-induced hyperthermic mice. Recently, a protein-protein interaction network has been established recently based on the functional-module analysis in which Fx and sargachromenol with 18 and 5 inflammatory protein networks showed huge response against 6 and 1 inflammatory modules via regulating the expression of I kappa B kinase (IKK)/NF- $\kappa$ B cascade respectively ${ }^{[87]}$.

\section{Cardiovascular protection effect:}

Fx from brown algae $U$. pinnatifida effectively deferred the progress of signs of strokes along with no significant alteration in blood pressure levels and enhanced life span of salt encumbered hypertensive rats $^{[88]}$. Various past studies reported that Fx is able to counteract myocardial apoptosis induced by doxorubicin (DOX), that would be further controlled by alternate splicing of apoptosis-related factors. Recently, a study demonstrated the mechanistic aspects of protection from DOX-induced injury in neonatal rat cardiomyocytes and the study reported that Fx induced DOX activated MAPK suppression and thereby resulting in cardio-protection. Moreover, cellular responses are mediated by MAPKs pathway as it can alter cell differentiation, proliferation, apoptosis and inflammation consisting of c-Jun N-terminal kinase (JNK), extracellular signal-regulated kinase (ERK) and $\mathrm{p} 38^{[89]}$. In this respect, Fx takes a major role by inhibiting DOX-induced JNK phosphorylation and $\mathrm{p} 38$, thereby leading to $\mathrm{p} 53$ activation, which is further directly linked with cardiomyocytes apoptosis ${ }^{[90]}$. Further attenuation of neuronal cell injury in hypoxia and re-oxygenation is promoted by $\mathrm{Fx}$, probably utilizing its radical quenching activity and based on this study, the researchers involved concluded that Fx could be beneficial against various ischaemic neuronal cell dysfunctioning in stroke vulnerable hypertensive rats and other cardiovascular diseases ${ }^{[88]}$. Recently, Menichini et al. ${ }^{[91]}$ tried to investigate the combination of Fx (F) and hydroxytyrosol $(\mathrm{H})$ with some insulin sensitizer compounds including Myoinositol (M) and D-chiro-inositol (D) in hypertensive pregnant mice model; a transgenic heterozygous mice model, having deficit of endothelial nitric oxide synthase gene (eNOS-/+) and environmental, wild-type (WT) mice. Results showed that systolic blood pressure reduced in WT dams and eNOS-/+ after dietary incorporation of Myoinositol, D-chiro-inositol, Fx, hydroxytyrosol (MDFH). In the case of eNOS-/+, MDFH subordinates the contractile response to N-nitro-L-arginine methyl ester (L-NAME) and phenylephrine (PE) and upgraded acetylcholine (ACh) vasorelaxation. Further, MDFH supplementation did not alter the PE responses in WT dams but lessened the vascular PE response after being incubated with L-NAME; thereby acting like a potential candidate against hypertension during pregnancy.

\section{Hepatoprotective effects:}

Fx can stimulate oxidation of fatty acid and thereby reduces hepatic lipid constituents, particularly via regulation of various metabolic enzymatic actions. When Fx rich HFD was administered to the C57BL/6N mice, it significantly lowered the lipid adsorption by reducing the hepatic lipids whereas faecal lipid and faeces weight have been exclusively increased [Woo et al. ${ }^{[29]}$. Park et al. ${ }^{[92]}$ reported the possible mechanistic aspects of Fx in reducing hepatic lipid droplet aggregation is due to inhibition of enzymes associated with hepatic fatty-acid synthesis ${ }^{[29,92]}$. Additionally, Fx can expressively upregulate enzymes related to glycolysis like GK in the liver and thereby improved hepatic GK/glucose-6-phosphatase ratio as well as glycogen content. This indicates that Fx may standardize concentrations of hepatic glycogen in highfat (HF) fed mice ${ }^{[92]}$. Increase in docosahexaenoic acid (DHA) may be a possible reason behind the reduction in activities of hepatic enzymes.

Fx and its major metabolite, fucoxanthinol, enhances the levels of DHA in the liver of both matured C57BL/6J mouse and KK- $\mathrm{A}^{\mathrm{y}}$ mice but DHA levels in the small intestine of both the mice didn't get altered ${ }^{[93]}$. In addition, Fx fed mice were also found with higher levels of arachidonic acid ( $\omega-6)$ and alterations in the metabolic pathways involving such unsaturated fatty acids were considered to be the reason behind this. Moreover, scientific investigation on the ameliorating effects of Fx against hepatic lipid peroxidation and hepatotoxicity showed that Fx might recover murine embryonic hepatic BNL CL.2 cell proliferation and 
also enhance the glutathione levels. Recent evidence on experimental animal models and in mature humans diagnosed with non-alcoholic fat liver disease (NAFLD) showed that Fx treated diets can induce DHA along with it, has both insulin-sensitizing properties and antiinflammatory effects, thereby indicating its promising role in dealing with NAFLD treatment ${ }^{[94]}$.

\section{Other nutraceutical effects:}

Oxidative damage of neuronal cells caused by peroxide and $\beta$-amyloid oligomers $(A \beta)$, can be protected by $\mathrm{Fx}$ and the mechanism is attributed to PI3K/Akt cascade activation and ERK pathway inhibition ${ }^{[95]}$. A $\beta$ oligomers are considered to be a major neurotoxin, responsible for Alzheimer's disease (AD). The potential reduction of formation of $A \beta$ oligomers both in vivo and in vitro makes Fx a potentially eligible candidate for $\mathrm{AD}$ treatment ${ }^{[96]}$. Fx can also decline the levels of oxidative stress as well as inflammation in A $\beta 42$-induced BV-2 microglia cells which may be responsible for neuronal degeneration in $\mathrm{AD}$ patients. Besides, experimentation on animal models showed that $\mathrm{Fx}$ could protect an entity from traumatic brain injury as well as middle cerebral artery occlusion ${ }^{[97]}$. Neuroprotective mechanism of Fx has not still been fully elucidated, but the interactions of Fx and brain-related key enzymes has been studied using molecular docking studies. Fx could also act as a potential dopamine agonist of D3/D4, which would have been utilizable in neurodegenerative disease management, most importantly Parkinson's disease ${ }^{[98]}$. In another site, levels of $\beta$-site amyloid precursor protein cleaving enzyme 1 (BACE1) got elevated at the onset of sporadic Alzheimer diseased brains. And this upregulation happens under several stress conditions like hypoxia, cerebral ischemia and ROS induced oxidative stress etc. Herein, Fx repressed the BACE1 enzymatic activity via molecular interaction between 2 additional BACE1 residues, including Ala127 and Gly11 and 2-OH groups on the Fx molecule ${ }^{[99]}$. Besides, neuron protection, the anti-angiogenic activity of Fx was demonstrated by Sugawara et al. ${ }^{[100]}$ using rat aortic ring and cultured endothelial cells of the human umbilical vein. They noticed that Fx and Fx$\mathrm{OH}$ both prohibited the outgrowth of the microvessels in the ex vivo angiogenic assay utilizing rat aortic ring, thereby recommending Fx to use against treatment angiogenesis-related dysfunctions, like diabetic retinopathy, cancer, psoriasis and atherosclerosis. Furthermore, Fx showed bone protective action by suppressing the osteoclastogenesis process via constraining differentiation of osteoclasts and tempting apoptosis in osteoclasts but did not provoke bone construction in any animals ${ }^{[101]}$.

\section{Cosmeceutical potential:}

Skin protective effects: Continuous exposure to UV-B led to the generation of inflammation, ROS, angiogenesis of skin and caused some skin disease such as laxity, pigmentation, erythema, wrinkling, skin cancer etc. In human fibroblasts, Fx can significantly decrease ROS generation ${ }^{[102]}$. Besides, Fx can inhibit the activity of enzyme tyrosinase, melanin formation in melanoma cells, skin pigmentation damage induced by UV-B. In view of the mechanistic aspect, oral or topical consumption of $\mathrm{Fx}$ significantly oppressed overexpression of endothelin receptor A, neurotrophin receptor $\mathrm{p} 75, \mathrm{COX}-2$, melanocortin receptor 1, prostaglandin Ereceptor 1 and tyrosinase induced protein 1, therefore suppressed prostaglandin $\mathrm{E}_{2}$ synthesis and melanogenic stimulant receptors and finally led to protection against UV-B induced melanogenesis. In a study, the skin degradation effect of extract and fractions of Padina australis have been investigated and the results depicted that anti-wrinkles of extract and fraction of $P$. australis showed better activity against elastase and collagenase enzymes compared to elastantinal and N-Isobutyl-N-(4-methoxyphenylsulfonyl (NNGH). The anti-melanogenic activity showed that extract, fractions and kojic acid have similar inhibition toward tyrosinase enzyme ${ }^{[103]}$. Rodríguez-Luna et al. ${ }^{[104]}$ further assessed the potential of Fx-comprising cream on 12-tetradecanoylphorbol-13-acetate induced cutaneal hyperplasia in the mouse model, along with on acute erythema induced by UV-B in hairless mouse. The creamy formulation thereby efficiently amended TPAinfluenced hyperplasia, through deducing cutaneous oedema, the thickness of epiderm, activity and expression of myeloperoxidase (MPO) and COX-2. Furthermore, Fx containing cream decreased UV-B tempted erythema via downregulating iNOS and COX2 and upregulating of HO-1 protein via Nrf-2 pathway, thereby preventing exacerbations associated with skin inflammatory pathologies and gives protection. Besides, Fx improved the adverse effects of ethanol and abridged expression of pro-inflammatory IL-6 and 8 , while enhancing expression of $\mathrm{N}$-acetyltransferase 1 (NAT1) gene when a group of scientists investigated the viability of tissue as per the organisation for economic co-operation and development (OECD) test guideline no. 439 , along with variations in homeostasis (estimated 
glomerular filtration rate (eGFR), heat shock protein beta-1 (HSPB1)), metabolism (NAT1) and inflammation (IL-1 $\alpha$, IL-6, IL-8) in animals ${ }^{[105]}$. Additionally, Fx can suppress vascular endothelial growth factor (VEGF), expression of matrix metalloproteinase 13 (MMP-13), epidermal hypertrophy, which is the main cause of wrinkle formation, as well as can increase the contents of thiobarbituric acid reactive constituents in skins of hairless mice ${ }^{[106]}$.

Oculo-protective effects: Fx depicts anti-proliferative actions against epithelial cell line of the human lens by apparently inhibiting human lens epithelial cell line (SRA01/04) that might cause post-cataract also called posterior capsule opacification (PCO), a long duration snag of the extracapsular cataract extraction ${ }^{[107]}$. Further, anti-ocular inflammation potential of Fx was studied by Shiratori et al. ${ }^{[108]}$ on male lewis rats diagnosed with lipopolysaccharide-tempted uveitis and observed that Fx stifled the progress of uveitis. Moreover, Liu et al. ${ }^{[109]}$ investigated the retinal damage protection against light-induced damage both in vivo and in vitro and the results from in vitro experiment provided that Fx could significantly display better biological activities than zeaxanthin, lutein and anthocyanins particularly in preventing upsurged expression of VEGF, senescence resistance, cleansing of intracellular ROS generation in epithelial cells present in retinal pigments and also improved functioning of phagocytes in vitro. Besides, in vivo results also give confirmation about the superiority of Fx over lutein against photo-induced retinal damage.

\section{Other effects:}

In an investigation study, brown seaweed Sargassum heterophyllum was chosen to extract some organic compounds for exhibiting antiplasmodial activity and therefore fractionated sargahydroquinoic acid, sargaquinoic acid, Fx and sargaquinal. Further experimental results suggested that Fx has the optimum antiplasmodial potential, whereas sargaquinal depicted good activity and rest two derivatives were only mild to moderately active ${ }^{[110]}$. Furthermore, photoprotection capacity of Fx extracts from 22 samples of marine macroalgae have been assessed and as suggested by different action spectra, Porphyra umbilicalis and Sargassum vulgare extracts provided potentially highest photoprotection with much greater increment in percent effective solar absorption radiation (\% ESAR) values against different analyzed biological responses ${ }^{[111]}$. This evaluation suggests that Fx possibly will be an operative UV protection constituent and can be utilized in sunscreens and cosmetics for shielding skin from photoaging. Furthermore, it would likely be well enough to investigate the consequence of oral absorption of Fx on the skin photoaging.

\section{CONCLUSION}

Continuous experimentation and tissue culture studies apprehend that Fx is enormously effective for reducing the vulnerability of incurable diseases like diabetes, obesity, tumours, inflammations, hypertension, heart and lung diseases etc., by influencing various molecular signalling pathways. Besides, the cosmetic connections of Fx and its metabolites can determine its function as cosmeceuticals like anti-tyrosinase (kojic acid), UV protection, antiacne, whitening, anti-oxidants and anti-wrinkle effects. The mechanism controlling all these bioactivities can be described based on the modulation of Fx on the signalling pathways related to the dysfunctions. The unique allenic bond and receptor protein interaction properties can be a possible reason for alleviating such potential against life-threatening diseases. Despite having high Fx profiles in some seaweeds, the bioavailability of it in human is still very low. However, the supplementary combination of Fx from diatoms or brown algae and lipid or palatable oil might intensify the absorption rate of Fx and could be emerged as a promising gifted marine drug. Further, much more extensive experimentation on animals and well managed clinical trials are highly suggested for further studies.

\section{Conflict of interests:}

The authors declared no conflict of interest.

\section{REFERENCES}

1. Reboleira J, Freitas R, Pinteus S, Silva J, Alves C, Pedrosa $\mathrm{R}$, et al. Brown seaweeds. In: Nonvitamin and nonmineral nutritional supplements. London, United Kingdom: Academic Press; 2019. p. 171-6.

2. Gupta S, Abu-Ghannam N. Bioactive potential and possible health effects of edible brown seaweeds. Trends Food Sci Technol 2011;22(6):315-26.

3. Lopes G, Andrade PB, Valentao P. Phlorotannins: Towards new pharmacological interventions for diabetes mellitus type 2. Molecules 2017;22(1):56.

4. Fernandez-Moriano C, Gomez-Serranillos MP, Crespo A. Antioxidant potential of lichen species and their secondary metabolites. Pharm Biol 2016;54(1):1-7.

5. Susanto E, Fahmi AS, Hosokawa M, Miyashita K. Variation in lipid components from 15 species of tropical and temperate seaweeds. Mar Drugs 2019;17(11):630.

6. Maeda H. Nutraceutical effects of fucoxanthin for obesity and diabetes therapy: a review. J Oleo Sci 2015:14226.

7. Peng J, Yuan JP, Wu CF, Wang JH. Fucoxanthin, a marine 
carotenoid present in brown seaweeds and diatoms: metabolism and bioactivities relevant to human health. Mar Drugs 2011;9(10):1806-28.

8. Kanazawa K, Ozaki Y, Hashimoto T, Das SK, Matsushita S, Hirano M, et al. Commercial-scale preparation of biofunctional fucoxanthin from waste parts of brown sea algae Laminalia japonica. Food Sci Technol Res 2008;14(6):573.

9. Nakazawa Y, Sashima T, Hosokawa M, Miyashita K. Comparative evaluation of growth inhibitory effect of stereoisomers of fucoxanthin in human cancer cell lines. J Funct Foods 2009;1(1):88-97.

10. Terasaki M. Evaluation of recoverable functional lipid components with special reference to fucoxanthin and fucosterot contents of several brown seaweeds of Japan. J Phycol 2009;45:974-80.

11. Terasaki M, Kawagoe C, Ito A, Kumon H, Narayan B, Hosokawa M, et al. Spatial and seasonal variations in the biofunctional lipid substances (fucoxanthin and fucosterol) of the laboratory-grown edible Japanese seaweed (Sargassum horneri Turner) cultured in the open sea. Saudi J Biol Sci 2017;24(7):1475-82.

12. Lourenço-Lopes C, Garcia-Oliveira P, Carpena M, FragaCorral M, Jimenez-Lopez C, Pereira AG, et al. Scientific approaches on extraction, purification and stability for the commercialization of fucoxanthin recovered from brown algae. Foods 2020;9(8):1113.

13. Miyashita K, Beppu F, Hosokawa M, Liu X, Wang S. Nutraceutical characteristics of the brown seaweed carotenoid fucoxanthin. Arch Biochem Biophys 2020;686:108364.

14. $\mathrm{Pu}$ J, Bechtel PJ, Sathivel S. Extraction of shrimp astaxanthin with flaxseed oil: effects on lipid oxidation and astaxanthin degradation rates. Biosyst Eng 2010;107(4):364-71.

15. Teramukai K, Kakui S, Beppu F, Hosokawa M, Miyashita K. Effective extraction of carotenoids from brown seaweeds and vegetable leaves with edible oils. Innov Food Sci Emerg Technol 2020;60:102302.

16. Unger RH, Orci L. Diseases of liporegulation: new perspective on obesity and related disorders. FASEB J 2001;15(2):312-21.

17. Bray GA, Tartaglia LA. Medicinal strategies in the treatment of obesity. Nature 2000;404:672-7.

18. Hu X, Li Y, Li C, Fu Y, Cai F, Chen Q, Li D. Combination of fucoxanthin and conjugated linoleic acid attenuates body weight gain and improves lipid metabolism in high-fat dietinduced obese rats. Arch Biochem Biophys 2012;519(1):5965.

19. Rasmussen BB, Holmback UC, Volpi E, Morio-Liondore B, Paddon-Jones D, Wolfe RR. Malonyl coenzyme A and the regulation of functional carnitine palmitoyltransferase-1 activity and fat oxidation in human skeletal muscle. J Clin Invest 2002;110(11):1687-93.

20. Wu M, Singh SB, Wang J, Chung CC, Salituro G, Karanam BV, et al. Antidiabetic and antisteatotic effects of the selective fatty acid synthase (FAS) inhibitor platensimycin in mouse models of diabetes. Proc Natl Acad Sci USA 2011;108(13):5378-83.

21. Beppu F, Hosokawa M, Niwano Y, Miyashita K. Effects of dietary fucoxanthin on cholesterol metabolism in diabetic/ obese KK-A y mice. Lipids Health Dis 2012;11(1):1-8.

22. Ntambi JM, Young-Cheul K. Adipocyte differentiation and gene expression. J Nutr 2000;130(12):3122S-6S.

23. Maeda H, Hosokawa M, Sashima T, Funayama K, Miyashita K. Fucoxanthin from edible seaweed, Undaria pinnatifida, shows antiobesity effect through UCP1 expression in white adipose tissues. Biochem Biophys Res Commun 2005;332(2):392-7.
24. Brown GC, Murphy MP, Jornayvaz FR, Shulman GI. Regulation of mitochondrial biogenesis. Essays Biochem 2010;47:69-84.

25. Heilbronn LK, Noakes M, Clifton PM. Energy restriction and weight loss on very-low-fat diets reduce C-reactive protein concentrations in obese, healthy women. Arterioscler Thromb Vasc Biol 2001;21(6):968-70.

26. Abidov M, Ramazanov Z, Seifulla R, Grachev S. The effects of Xanthigen ${ }^{\mathrm{TM}}$ in the weight management of obese premenopausal women with non-alcoholic fatty liver disease and normal liver fat. Diabetes Obes Metab 2010;12(1):72-81.

27. Hitoe S, Shimoda H. Seaweed fucoxanthin supplementation improves obesity parameters in mild obese Japanese subjects. Funct Foods Health Dis 2017;7(4):246-62.

28. Maeda H, Hosokawa M, Sashima T, Murakami-Funayama K, Miyashita K. Anti-obesity and anti-diabetic effects of fucoxanthin on diet-induced obesity conditions in a murine model. Mol Med Rep 2009;2(6):897-902.

29. Woo MN, Jeon SM, Kim HJ, Lee MK, Shin SK, Shin YC, et al. Fucoxanthin supplementation improves plasma and hepatic lipid metabolism and blood glucose concentration in high-fat fed C57BL/6N mice. Chem Biol Interact 2010;186(3):316-22.

30. Maeda H, Hosokawa M, Sashima T, Takahashi N, Kawada T, Miyashita K. Fucoxanthin and its metabolite, fucoxanthinol, suppress adipocyte differentiation in 3T3-L1 cells. Int J Mol Med 2006;18(1):147-52.

31. Kang SI, Ko HC, Shin HS, Kim HM, Hong YS, Lee NH, et al. Fucoxanthin exerts differing effects on 3T3-L1 cells according to differentiation stage and inhibits glucose uptake in mature adipocytes. Biochem Biophys Res Commun 2011;409(4):76974.

32. Beppu F, Hosokawa M, Yim MJ, Shinoda T, Miyashita K. Down-regulation of hepatic stearoyl-CoA desaturase-1 expression by Fucoxanthin via leptin signaling in diabetic/ obese KK-Ay mice. Lipids 2013;48(5):449-55.

33. Koo SY, Hwang JH, Yang SH, Um JI, Hong KW, Kang K, et al. Anti-obesity effect of standardized extract of microalga Phaeodactylum tricornutum containing fucoxanthin. Mar Drugs 2019;17(5):311.

34. Sun X, Zhao H, Liu Z, Sun X, Zhang D, Wang S, et al. Modulation of gut microbiota by fucoxanthin during alleviation of obesity in high-fat diet-fed mice. J Agric Food Chem 2020;68(18):5118-28.

35. Gille A, Stojnic B, Derwenskus F, Trautmann A, SchmidStaiger U, Posten C, et al. A lipophilic fucoxanthin-rich Phaeodactylum tricornutum extract ameliorates effects of dietinduced obesity in C57BL/6J mice. Nutrients 2019;11(4):796.

36. Guo B, Yang B, Pang X, Chen T, Chen F, Cheng KW. Fucoxanthin modulates cecal and fecal microbiota differently based on diet. Food Funct 2019;10(9):5644-55.

37. Chang YH, Chen YL, Huang WC, Liou CJ. Fucoxanthin attenuates fatty acid-induced lipid accumulation in FL83B hepatocytes through regulated Sirt1/AMPK signaling pathway. Biochem Biophys Res Commun 2018;495(1):197-203.

38. Se S. Lee J. Goldfine AB. Inflammation and insulin resistance. J Clin Invest 2006;116:1793-801.

39. Huang S, Czech MP. The GLUT4 glucose transporter. Cell Metab 2007;5(4):237-52.

40. Nishikawa S, Hosokawa M, Miyashita K. Fucoxanthin promotes translocation and induction of glucose transporter 4 in skeletal muscles of diabetic/obese KK-Ay mice. Phytomedicine 2012;19(5):389-94.

41. Hosokawa M, Miyashita T, Nishikawa S, Emi S, Tsukui T, 
Beppu F, et al. Fucoxanthin regulates adipocytokine mRNA expression in white adipose tissue of diabetic/obese KK-Ay mice. Arch Biochem Biophys 2010;504(1):17-25.

42. Woo MN, Jeon SM, Kim HJ, Lee MK, Shin SK, Shin YC, et al. Fucoxanthin supplementation improves plasma and hepatic lipid metabolism and blood glucose concentration in high-fat fed C57BL/6N mice. Chem Biol Interact 2010;186(3):316-22.

43. Kim KM, Kim SM, Cho DY, Park SJ, Joo NS. The effect of xanthigen on the expression of brown adipose tissue assessed by 18F-FDG PET. Yonsei Med J 2016;57(4):1038-41.

44. Miyashita K, Hosokawa M. Therapeutic effect of fucoxanthin on metabolic syndrome and type 2 diabetes. In nutritional and therapeutic interventions for diabetes and metabolic syndrome. Academic Press; 2018. p. 343-55.

45. Kawee-Ai A, Kim AT, Kim SM. Inhibitory activities of microalgal fucoxanthin against $\alpha$-amylase, $\alpha$-glucosidase and glucose oxidase in 3T3-L1 cells linked to type 2 diabetes. J Oceanol Limnol 2019;37(3):928-37.

46. Nandipati KC, Subramanian S, Agrawal DK. Protein kinases: mechanisms and downstream targets in inflammationmediated obesity and insulin resistance. Mol Cell Biochem 2017;426:27-45.

47. Nikoulina SE, Ciaraldi TP, Mudaliar S, Mohideen P, Carter L, Henry RR. Potential role of glycogen synthase kinase-3 in skeletal muscle insulin resistance of type 2 diabetes. Diabetes 2000;49(2):263-71.

48. Zhang Y, Xu W, Huang X, Zhao Y, Ren Q, Hong Z, et al. Fucoxanthin ameliorates hyperglycemia, hyperlipidemia and insulin resistance in diabetic mice partially through IRS-1/ PI3K/Akt and AMPK pathways. J Funct Foods 2018;48:51524.

49. Jung HJ, Jung HA, Kang SS, Lee JH, Cho YS, Moon KH, et al. Inhibitory activity of Aralia continentalis roots on protein tyrosine phosphatase $1 \mathrm{~B}$ and rat lens aldose reductase. Arch Pharm Res 2012;35(10):1771-7.

50. Sachindra NM, Sato E, Maeda H, Hosokawa M, Niwano Y, Kohno M, et al. Radical scavenging and singlet oxygen quenching activity of marine carotenoid fucoxanthin and its metabolites. J Agric Food Chem 2007;55(21):8516-22.

51. Hirayama O, Nakamura K, Hamada S, Kobayasi Y. Singlet oxygen quenching ability of naturally occurring carotenoids. Lipids 1994;29(2):149-50.

52. Miyashita K, Hosokawa M. Health impact of marine carotenoids. J Food Bioact 2018;1:31-40.

53. Shin T, Ahn M, Hyun JW, Kim SH, Moon C. Antioxidant marine algae phlorotannins and radioprotection: A review of experimental evidence. Acta Histochem 2014;116(5):669-74.

54. Nomura T, Kikuchi M, Kubodera A, Kawakami Y. Protondonative antioxidant activity of fucoxanthin with 1,1-diphenyl2-picrylhydrazyl (DPPH). IUBMB Life 1997;42(2):361-70.

55. Sangeetha RK, Bhaskar N, Baskaran V. Comparative effects of $\beta$-carotene and fucoxanthin on retinol deficiency induced oxidative stress in rats. Mol Cell Biochem 2009;331(1):59-67.

56. Neumann U, Derwenskus F, Flaiz Flister V, Schmid-Staiger U, Hirth T, Bischoff SC. Fucoxanthin, a carotenoid derived from Phaeodactylum tricornutum exerts antiproliferative and antioxidant activities in vitro. Antioxidants 2019;8(6):183.

57. Foo SC, Khong NM, Yusoff FM. Physicochemical, microstructure and antioxidant properties of microalgaederived fucoxanthin rich microcapsules. Algal Res 2020;51:102061.

58. Heo SJ, Ko SC, Kang SM, Kang HS, Kim JP, Kim SH, et al. Cytoprotective effect of fucoxanthin isolated from brown algae
Sargassum siliquastrum against $\mathrm{H}_{2} \mathrm{O}_{2}$-induced cell damage. Eur Food Res Technol 2008;228(1):145-51.

59. Zeng J, Zhang Y, Ruan J, Yang Z, Wang C, Hong Z, et al. Protective effects of fucoxanthin and fucoxanthinol against tributyltin-induced oxidative stress in HepG2 cells. Environ Sci Pollut Res 2018;25(6):5582-9.

60. Pangestuti R, Vo TS, Ngo DH, Kim SK. Fucoxanthin ameliorates inflammation and oxidative reponses in microglia. J Agric Food Chem 2013;61(16):3876-83.

61. Liu CL, Chiu YT, Hu ML. Fucoxanthin enhances HO-1 and NQO1 expression in murine hepatic BNL CL. 2 cells through activation of the Nrf2/ARE system partially by its pro-oxidant activity. J Agric Food Chem 2011;59(20):11344-51.

62. Kaneko M, Nagamine T, Nakazato K, Mori M. The antiapoptotic effect of fucoxanthin on carbon tetrachloride-induced hepatotoxicity. J Toxicol Sci 2013;38(1):115-26.

63. Yamamoto K, Ishikawa C, Katano H, Yasumoto T, Mori N. Fucoxanthin and its deacetylated product, fucoxanthinol, induce apoptosis of primary effusion lymphomas. Cancer Lett 2011;300(2):225-34.

64. Ishikawa C, Tafuku S, Kadekaru T, Sawada S, Tomita M, Okudaira $\mathrm{T}$, et al. Antiadult T-cell leukemia effects of brown algae fucoxanthin and its deacetylated product, fucoxanthinol. Int J Cancer 2008;123(11):2702-12.

65. Garg S, Afzal S, Elwakeel A, Sharma D, Radhakrishnan N, Dhanjal JK, et al. Marine carotenoid fucoxanthin possesses anti-metastasis activity: Molecular evidence. Mar Drugs 2019;17(6):338.

66. Ganesan P, Noda K, Manabe Y, Ohkubo T, Tanaka Y, Maoka T, et al. Siphonaxanthin, a marine carotenoid from green algae, effectively induces apoptosis in human leukemia (HL-60) cells. Biochim Biophys Acta Gen Subj 2011;1810(5):497-503.

67. Kotake-Nara E, Kushiro M, Zhang H, Sugawara T, Miyashita K, Nagao A. Carotenoids affect proliferation of human prostate cancer cells. J Nutr 2001;131(12):3303-6.

68. Moreau D, Tomasoni C, Jacquot C, Kaas R, Le Guedes R, Cadoret JP, et al. Cultivated microalgae and the carotenoid fucoxanthin from Odontella aurita as potent anti-proliferative agents in bronchopulmonary and epithelial cell lines. Environ Toxicol Pharmacol 2006;22(1):97-103.

69. Takahashi K, Hosokawa M, Kasajima H, Hatanaka K, Kudo $\mathrm{K}$, Shimoyama N, et al. Anticancer effects of fucoxanthin and fucoxanthinol on colorectal cancer cell lines and colorectal cancer tissues. Oncol Lett 2015;10(3):1463-7.

70. Terasaki M, Maeda H, Miyashita K, Tanaka T, Miyamoto S, Mutoh M. A marine bio-functional lipid, fucoxanthinol, attenuates human colorectal cancer stem-like cell tumorigenicity and sphere formation. J Clin Biochem Nutr 2017:16-12.

71. Terasaki M, Mima M, Kudoh S, Endo T, Maeda H, Hamada $\mathrm{J}$, et al. Glycine and succinic acid are effective indicators of the suppression of epithelial-mesenchymal transition by fucoxanthinol in colorectal cancer stem-like cells. Oncol Rep 2018;40(1):414-24.

72. Zhang Z, Zhang P, Hamada M, Takahashi S, Xing G, Liu J, et al. Potential chemoprevention effect of dietary fucoxanthin on urinary bladder cancer EJ-1 cell line. Oncol Rep 2008;20(5):1099-103.

73. Das SK, Hashimoto T, Kanazawa K. Growth inhibition of human hepatic carcinoma HepG2 cells by fucoxanthin is associated with down-regulation of cyclin D. Biochim Biophys Acta Gen Subj 2008;1780(4):743-9.

74. Li Y, Tao L, Bao L, Chinnathambi A, Alharbi SA, Cui J. 
Fucoxanthin inhibits cell proliferation and stimulates apoptosis through downregulation of $\mathrm{PI} 3 \mathrm{~K} / \mathrm{AKT} / \mathrm{mTOR}$ signaling pathway in human ovarian cancer cells. Pharmacogn Mag 2020;16(69):311.

75. Das SK, Hashimoto T, Baba M, Nishino H, Komoto A, Kanazawa K. Japanese kelp (kombu) extract suppressed the formation of aberrant crypt foci in azoxymethane challenged mouse colon. J Clin Biochem Nutr 2006;38(2):119-25.

76. Terasaki M, Masaka S, Fukada C, Houzaki M, Endo T, Tanaka $\mathrm{T}$, et al. Salivary glycine is a significant predictor for the attenuation of polyp and tumor microenvironment formation by fucoxanthin in AOM/DSS mice. In vivo 2019;33(2):365-74.

77. Okuzumi J, Takahashi T, Yamane T, Kitao Y, Inagake M, Ohya $\mathrm{K}$, et al. Inhibitory effects of fucoxanthin, a natural carotenoid, on N-ethyl-N'-nitro-N-nitrosoguanidine-induced mouse duodenal carcinogenesis. Cancer Lett 1993;68:159-68.

78. Wang Z, Li H, Dong M, Zhu P, Cai Y. The anticancer effects and mechanisms of fucoxanthin combined with other drugs. $J$ Cancer Res Clin Oncol 2019;145(2):293-301.

79. Chen L, Deng H, Cui H, Fang J, Zuo Z, Deng J, et al. Inflammatory responses and inflammation-associated diseases in organs. Oncotarget 2018;9(6):7204.

80. Muller WA. Getting leukocytes to the site of inflammation. Vet Pathol 2013;50(1):7-22.

81. Sakai S, Sugawara T, Matsubara K, Hirata T. Inhibitory effect of carotenoids on the degranulation of mast cells via suppression of antigen-induced aggregation of high affinity IgE receptors. J Biol Chem 2009;284(41):28172-9.

82. Su J, Guo K, Huang M, Liu Y, Zhang J, Sun L, et al. Fucoxanthin, a marine xanthophyll isolated from Conticribra weissflogii ND-8: Preventive anti-inflammatory effect in a mouse model of sepsis. Front Pharmacol 2019;10:906.

83. Yang YP, Tong QY, Zheng SH, Zhou MD, Zeng YM, Zhou TT. Anti-inflammatory effect of fucoxanthin on dextran sulfate sodium-induced colitis in mice. Nat Prod Res 2020;34(12):1791-5.

84. Hwang PA, Phan NN, Lu WJ, Hieu BT, Lin YC. Lowmolecular-weight fucoidan and high-stability fucoxanthin from brown seaweed exert prebiotics and anti-inflammatory activities in Caco-2 cells. Food Nutr Res 2016;60(1):32033.

85. Rodríguez-Luna A, Avila-Roman J, Oliveira H, Motilva V, Talero E. Fucoxanthin and rosmarinic acid combination has anti-inflammatory effects through regulation of NLRP3 inflammasome in UVB-exposed HaCaT keratinocytes. Mar Drugs 2019;17(8):451.

86. Khan MN, Choi JS, Lee MC, Kim E, Nam TJ, Fujii H, et al. Anti-inflammatory activities of methanol extracts from various seaweed species. J Environ Biol 2008;29(4):465-9.

87. Sornsiri J, Srisook K, Pornngam P, Sootanan P. Prediction of biochemical mechanism of anti-inflammation explained from two marine-derived bioactive compounds. Agric Nat Resour 2018;52(6):588-95.

88. Ikeda K, Kitamura A, Machida H, Watanabe M, Negishi H, Hiraoka J, et al. Effect of Undaria pinnatifida (Wakame) on the development of cerebrovascular diseases in stroke-prone spontaneously hypertensive rats. Clin Exp Pharmacol Physiol 2003;30(1-2):44-8.

89. Johnson GL, Lapadat R. Mitogen-activated protein kinase pathways mediated by ERK, JNK and p38 protein kinases. Science 2002;298:1911-2.

90. Zhao YQ, Zhang L, Zhao GX, Chen Y, Sun KL, Wang B. Fucoxanthin attenuates doxorubicin-induced cardiotoxicity via anti-oxidant and anti-apoptotic mechanisms associated with p38, JNK and p53 pathways. J Funct Foods 2019;62:103542.

91. Menichini D, Alrais M, Liu C, Xia Y, Blackwell SC, Facchinetti $\mathrm{F}$, et al. Maternal supplementation of inositols, fucoxanthin and hydroxytyrosol in pregnant murine models of hypertension. Am J Hypertens 2020;33(7):652-9.

92. Park HJ, Lee MK, Park YB, Shin YC, Choi MS. Beneficial effects of Undaria pinnatifida ethanol extract on diet-inducedinsulin resistance in $\mathrm{C} 57 \mathrm{BL} / 6 \mathrm{~J}$ mice. Food Chem Toxicol 2011;49(4):727-33.

93. Tsukui T, Baba N, Hosokawa M, Sashima T, Miyashita K. Enhancement of hepatic docosahexaenoic acid and arachidonic acid contents in C57BL/6J mice by dietary fucoxanthin. Fish Sci 2009;75(1):261-3.

94. Chang YH, Chen YL, Huang WC, Liou CJ. Fucoxanthin attenuates fatty acid-induced lipid accumulation in FL83B hepatocytes through regulated Sirt1/AMPK signaling pathway. Biochem Biophys Res Commun 2018;495(1):197-203.

95. Yu J, Lin JJ, Yu R, He S, Wang QW, Cui W, et al. Fucoxanthin prevents $\mathrm{H}_{2} \mathrm{O}_{2}$-induced neuronal apoptosis via concurrently activating the PI3-K/Akt cascade and inhibiting the ERK pathway. Food Nutr Res 2017;61(1):1304678.

96. Xiang S, Liu F, Lin J, Chen H, Huang C, Chen L, et al. Fucoxanthin inhibits $\beta$-amyloid assembly and attenuates $\beta$-amyloid oligomer-induced cognitive impairments. J Agric Food Chem 2017;65(20):4092-102.

97. Hu L, Chen W, Tian F, Yuan C, Wang H, Yue H. Neuroprotective role of fucoxanthin against cerebral ischemic/reperfusion injury through activation of $\mathrm{Nrf} 2 / \mathrm{HO}-1$ signaling. Biomed Pharmacother 2018;106:1484-9.

98. Paudel P, Seong SH, Jung HA, Choi JS. Characterizing fucoxanthin as a selective dopamine D3/D4 receptor agonist: Relevance to Parkinson's disease. Chem Biol Interact 2019;310:108757.

99. Jung HA, Ali MY, Choi RJ, Jeong HO, Chung HY, Choi JS. Kinetics and molecular docking studies of fucosterol and fucoxanthin, BACE1 inhibitors from brown algae Undaria pinnatifida and Ecklonia stolonifera. Food Chem Toxicol 2016;89:104-11.

100. Sugawara T, Matsubara K, Akagi R, Mori M, Hirata T. Antiangiogenic activity of brown algae fucoxanthin and its deacetylated product, fucoxanthinol. J Agric Food Chem 2006;54(26):9805-10.

101. Das SK, Ren R, Hashimoto T, Kanazawa K. Fucoxanthin induces apoptosis in osteoclast-like cells differentiated from RAW264. 7 cells. J Agric Food Chem 2010;58(10):6090-5.

102. Heo SJ, Jeon YJ. Protective effect of fucoxanthin isolated from Sargassum siliquastrum on UV-B induced cell damage. J Photochem Photobiol B 2009;95(2):101-7.

103. Nurrochmad A. Antioxidant, anti-wrinkle and tyrosinase inhibitor of brown seaweed (Padina australis). In $1^{\text {st }}$ Int Conf Adv Pharm Pharm Sci; 2016.

104. Rodriguez-Luna A, Avila-Roman J, Oliveira H, Motilva V, Talero E. Fucoxanthin and rosmarinic acid combination has anti-inflammatory effects through regulation of NLRP3 inflammasome in UVB-exposed $\mathrm{HaCaT}$ keratinocytes. Mar Drugs 2019;17(8):451.

105. Spagolla Napoleao Tavares R, Stuchi Maria-Engler S, Colepicolo P, Debonsi HM, Schäfer-Korting M, Marx U, et al. Skin irritation testing beyond tissue viability: Fucoxanthin effects on inflammation, homeostasis and metabolism. Pharmaceutics 2020;12(2):136.

106. Urikura I, Sugawara T, Hirata T. Protective effect of 
fucoxanthin against UVB-induced skin photoaging in hairless mice. Biosci Biotechnol Biochem 2011;75(4):757-60.

107. Moreau D, Tomasoni C, Jacquot C, Kaas R, Le Guedes R, Cadoret JP, et al. Cultivated microalgae and the carotenoid fucoxanthin from Odontella aurita as potent anti-proliferative agents in bronchopulmonary and epithelial cell lines. Environ Toxicol Pharmacol 2006;22(1):97-103.

108. Shiratori K, Ohgami K, Ilieva I, Jin XH, Koyama Y, Miyashita $\mathrm{K}$, et al. Effects of fucoxanthin on lipopolysaccharide-induced inflammation in vitro and in vivo. Exp Eye Res 2005;81(4):4 $22-8$.

109. Liu Y, Liu M, Zhang X, Chen Q, Chen H, Sun L, et al. Protective effect of fucoxanthin isolated from Laminaria japonica against visible light-induced retinal damage both in vitro and in vivo. J Agric Food Chem 2016;64(2):416-24.

110. Afolayan AF, Bolton JJ, Lategan CA, Smith PJ, Beukes DR. Fucoxanthin, tetraprenylated toluquinone and toluhydroquinone metabolites from Sargassum heterophyllum inhibit the in vitro growth of the malaria parasite Plasmodium falciparum. Z Naturforsch C 2008;63:848-52.

111. Schneider G, Figueroa FL, Vega J, Chaves P, Alvarez-Gomez $\mathrm{F}$, Korbee $\mathrm{N}$, et al. Photoprotection properties of marine photosynthetic organisms grown in high ultraviolet exposure areas: Cosmeceutical applications. Algal Res 2020;49:101956. 